\title{
WEB Treatment of Intracranial Aneurysms: Clinical and Anatomic Results in the French Observatory
}

\author{
(D). Pierot, (D). Moret, (D). Turjman, (DD. Herbreteau, (DH. Raoult, (DX. Barreau, Ds. Velasco, (DH. Desal, (D) A.-C. Januel,
} (D). Courtheoux, (D).-Y. Gauvrit, (DC. Cognard, (D)A. Molyneux, (D). Byrne, and DL. Spelle

\begin{abstract}
BACKGROUND AND PURPOSE: Flow disruption with the WEB device is a new technique for the endovascular treatment of wide-neck bifurcation aneurysms. To obtain precise data regarding the safety and efficacy of this treatment with high-quality methodology, the prospective French Observatory study was conducted. Analysis of these data is presented, including 1-year follow-up.
\end{abstract}

MATERIALS AND METHODS: Patients with bifurcation aneurysms for which WEB treatment was indicated were included in this prospective, multicenter Good Clinical Practice study. Clinical data, including adverse events and clinical status at 1 month and 1 year, were collected and independently analyzed by a medical monitor. An independent core laboratory evaluated the anatomic results at 1 year following the procedure.

RESULTS: Ten French neurointerventional centers included 62 patients (39 women), 33-74 years of age (mean, $56.6 \pm 9.80$ years) with 63 aneurysms. Aneurysm locations were the middle cerebral artery in 32 aneurysms (50.8\%), anterior communicating artery in 16 ( $25.4 \%$ ), basilar artery in 9 (14.3\%), and internal carotid artery terminus in 6 (9.5\%). Morbidity and mortality at 1 month were, respectively, $3.2 \%(2 / 62$ patients) and $0.0 \%$ (0/62). Morbidity and mortality (unrelated to the treatment) at 1 year were, respectively, $0.0 \%(0 / 59)$ and $3.4 \%(2 / 59$ patients). At 1 year, complete occlusion was observed in 30/58 aneurysms (51.7\%); neck remnant, in 16/58 aneurysms (27.6\%); and aneurysm remnant, in $12 / 58$ aneurysms $(20.7 \%)$.

CONCLUSIONS: This prospective French Observatory study showed very good safety of aneurysm treatment with the WEB, with a high rate of adequate aneurysm occlusion at 1 year (79.3\%).

ABBREVIATIONS: DL = Dual-Layer; SL = Single-Layer; SLS = Single-Layer Spherical; WEBCAST = WEB Clinical Assessment of IntraSaccular Aneurysm Therapy

$\mathbf{E}^{\mathrm{n}}$ ndovascular treatment is now the first-line therapy for both ruptured and unruptured aneurysms, but aneurysms with a complex anatomy (especially wide-neck aneurysms) are, in some cases, untreatable or difficult to treat with standard coiling. ${ }^{1,2}$

Received June 15, 2015; accepted after revision July 30.

From the Department of Neuroradiology (L.P.), Hôpital Maison-Blanche, Université Reims-Champagne-Ardenne, Reims, France; Hôpital Beaujon, (J.M., L.S.), Assistance Publique-Hôpitaux de Paris, Clichy, France; Centre Hospitalier Universitaire de Lyon (F.T.), Lyon, France; Centre Hospitalier Universitaire de Tours (D.H.), Tours, France; Centre Hospitalier Universitaire de Rennes (H.R., J.-Y.G.), Rennes, France; Centre Hospitalier Universitaire de Bordeaux (X.B.), Bordeaux, France; Centre Hospitalier Universitaire de Poitiers (S.V.), Poitiers, France; Centre Hospitalier Universitaire de Nantes (H.D.), Nantes, France; Centre Hospitalier Universitaire de Toulouse (A.-C.J., C.C.), Toulouse, France; Centre Hospitalier Universitaire de Caen (P.C.), Caen, France; and Oxford Neurovascular and Neuroradiology Research Unit (A.M., J.B.), Oxford Radcliffe Hospital, Oxford, UK.

The French Observatory was financially supported by Sequent Medical.

Conflict of interest: L.P., D.H., C.C., A.M., and L.S. have proctoring/consulting contracts with Sequent Medical.

Please address correspondence to Laurent Pierot, MD, PhD, Department of Neuroradiology, Hôpital Maison-Blanche, 45, Rue Cognacq-Jay 51092 Reims Cedex; e-mail: Ipierot@gmail.com

http://dx.doi.org/10.3174/ajnr.A4578
Thus, more complex endovascular techniques have been developed, such as balloon-assisted coiling, stent-assisted coiling, and flow diversion. ${ }^{3-9}$

Flow disruption is a new endovascular approach, which involves placement of an intrasaccular device (Woven EndoBridge [WEB] aneurysm embolization system; Sequent Medical, Aliso Viejo, California), which modifies the blood flow at the level of the neck and induces aneurysmal thrombosis. The WEB was designed to treat wide-neck and bifurcation aneurysms. The device has been progressively developed from a Dual-Layer version (WEB DL) to Single-Layer (WEB SL) and Single-Layer Spherical (WEB SLS) versions. Treatment with the WEB has been evaluated in several retrospective series showing good safety results. ${ }^{10-13}$ In addition, midterm and long-term anatomic results have been evaluated in retrospective series showing good stability of the treatment. ${ }^{14,15}$

To have a more rigorous evaluation of the safety and efficacy, 2 prospective, Good Clinical Practice series were initiated simultaneously in Europe (WEB Clinical Assessment of IntraSaccular 
Aneurysm Therapy [WEBCAST]) and in France (French Observatory). The short-term (6-month) results of the WEBCAST trial and a comparison of safety between the WEB DL and WEB SL/SLS in the French Observatory were published previously. ${ }^{16,17}$ These initial analyses confirmed the good safety and efficacy of the device in the short-term. This article reports the clinical and anatomic results of the French Observatory study with midterm (1year) follow-up.

\section{MATERIALS AND METHODS}

The French Observatory is a single-arm, prospective, consecutive, multicenter, French study dedicated to the evaluation of WEB treatment for bifurcation aneurysms.

The study received national regulatory authorization (Comité Consultatif sur le Traitement de l'Information en matière de Recherche dans le domiaine de la Santé), Reims institutional review board approval, and Commission Nationale Informatique et Libertés approval. Written informed consent was obtained for all patients.

\section{Trial Design and Procedural Modalities}

Trial design and procedural modalities have already been described in a previous publication. ${ }^{16}$ Briefly, inclusion criteria were ruptured (Hunt and Hess 1, 2, or 3), unruptured, and recanalized bifurcation aneurysms located in the basilar artery, middle cerebral artery, anterior communicating artery, and internal carotid artery terminus. In each center, the indication for endovascular treatment was decided by a local multidisciplinary team, which included neurosurgeons and neuroradiologists. The selection of aneurysms treated with the WEB device was performed autonomously in each center by the interventional neuroradiologists according to aneurysm characteristics (aneurysm status, aneurysm location and size, neck size) and when other therapeutic options like stent placement or flow diversion were deemed technically difficult or impossible.

The treatment of aneurysms with the WEB was performed with techniques similar to those used in the treatment of aneurysms with coils. Pre-, intra-, and postoperative antiplatelet therapy was managed in each center as indicated for typical endovascular treatment with coils or stents and coils. The study protocol did not specify the antiplatelet regimen to be followed. Triaxial access was recommended. Appropriate device sizing was selected on the basis of $2 \mathrm{D}$ and $3 \mathrm{D}$ digital subtraction angiography. According to the size of the WEB device, different microcatheters were used to catheterize the aneurysm, including Rebar-27 (Covidien, Irvine, California), DAC 038 (Stryker Neurovascular, Kalamazoo, Michigan), and, from late 2012 to the end of the trial, microcatheters dedicated to WEB treatment, including VIA-27 and VIA-33 (Sequent Medical). Treatment with ancillary devices (balloon, coils, and stents) could be performed if deemed necessary by the treating physician.

\section{Data Collection}

Each center completed a patient file with the following data: patient age and sex; aneurysm rupture status; aneurysm characteristics, including location, size, and neck size; date of the procedure; type of device used (DL or SL/SLS); perioperative antiplatelet medications; occurrence of complications during or after the procedure; and use of additional devices during the procedure (coils, remodeling balloons, stents, or flow diverters). The preoperative Hunt and Hess grade was collected in case of ruptured aneurysms. The modified Rankin Scale score was collected before treatment (unruptured/recanalized aneurysms) and at $30 \pm 7$ days and $12 \pm 3$ months for all patients. Vascular imaging at 1 year was collected.

\section{Data Analysis}

Clinical data were independently monitored and analyzed, including all adverse events (A.M.). Morbidity was defined as an $\mathrm{mRS}$ of 2 when the preoperative mRS was $\leq 2$ (or in case of a ruptured aneurysm). When the preoperative mRS was $>2$, morbidity was defined as as an increase of 1 point.

An expert interventional neuroradiologist (J.B.) independently evaluated aneurysm occlusion by using the previously validated 3-grade scale: complete occlusion, neck remnant, and aneurysm remnant. According to previous publications, opacification of the proximal recess of the WEB device was considered complete occlusion. ${ }^{14,18}$

\section{Statistical Analysis}

Continuous variables were described as mean \pm SD. Categoric data were described numerically as a categoric total and as a percentage of the population analyzed. Binomial data were described as a ratio of the true value and the population analyzed $(\mathrm{x} / \mathrm{n})$. Confidence intervals for binomial data were calculated by the Clopper-Pearson method, and $P$ values were calculated by the Fisher exact test. Analyses were conducted by using SPSS statistical software (IBM, Armonk, New York) and StatXact-8 (Cytel, Cambridge, Massachusetts) for confidence intervals and $P$ values.

\section{RESULTS}

\section{Patient and Aneurysm Population}

Between November 2012 and January 2014, 10 French centers included 62 patients (39 women, 62.9\%), 33-74 years of age (mean, $56.6 \pm 9.80$ years) with 63 aneurysms.

Seven (11.1\%) aneurysms were ruptured, 51 (81.0\%) were unruptured, and 5 (7.9\%) were previously treated but recanalized. Aneurysm locations were the MCA in 32 aneurysms (50.8\%), anterior communicating artery in $16(25.4 \%)$, basilar artery in $9(14.3 \%)$, and ICA terminus in $6(9.5 \%)$. The aneurysm neck was $\geq 4 \mathrm{~mm}$ in $57 / 63$ aneurysms $(90.5 \%)$. Fifty-two aneurysms $(82.5 \%)$ were $<10 \mathrm{~mm}$ in size.

Thirty patients with 31 aneurysms were treated with the WEB DL; and 32 patients with 32 aneurysms, with the WEB SL/SLS.

Before the procedure, 10 patients had no antiplatelet treatment, 26 patients had 1 antiplatelet medication (clopidogrel or aspirin), and 25 patients had 2 antiplatelet medications. For 1 patient, the antiplatelet therapy regimen could not be confirmed. He was excluded from further analysis regarding this point because he had no thromboembolic event. 


\section{Treatment Feasibility, Adjunctive Treatments, and Adverse Events}

Treatment was successfully performed in all except 1 patient treated with the WEB DL (98.4\%). In this patient, it was impossible to deploy the WEB, which was stuck in the microcatheter. The aneurysm was treated with coils. Clinical follow-up was uneventful.

Adjunctive devices were used in 7/62 aneurysms treated with the WEB (11.3\%): coils in 4 aneurysms and a stent in 3 aneurysms.

Nine thromboembolic events were reported in $8 / 62$ patients (12.9\%), and $1 / 62$ was associated with a permanent deficit (1.6\%). Five patients had no antiplatelet agent before the procedure, 1 patient had 1 antiplatelet agent, and 2 had 2 antiplatelet agents. All thromboembolic events were treated by antiplatelet medication, including tirofiban or abciximab. In 3 patients, a remodeling balloon was used in combination with antiplatelet treatment to reopen the vessel. No stent retriever or stent was used.

Intraoperative rupture was reported in $1 / 62$ patients $(1.6 \%)$ and was not symptomatic. Intracranial hemorrhage was detected in $1 / 62$ patients $(1.6 \%)$ on a control CT performed 24 hours after the procedure and was asymptomatic. Anatomically, it was not connected with the aneurysm. Because there was no other cause, it was interpreted by the medical monitor as being related to the antiplatelet treatment used in this patient. The clinical evolution was uneventful.

\section{Mortality/Morbidity at 1 Month}

At 30 days, all patients enrolled in the study had a clinical evaluation with mRS scoring.

There was no mortality at 1 month. Morbidity was observed in $2 / 62$ patients $(3.2 \%)$ related to a thromboembolic event in 1 patient (mRS 3 ) and to worsening of pre-existing aneurysm mass effect in 1 patient (this patient had a partially thrombosed large aneurysm of the basilar artery with progressive brain stem compression, mRS 3). When we looked at the conventional mRS score cohorts of mRS $0-2$ and mRS 3-6, the confidence intervals essentially overlapped; this finding implied no difference in the rates of mRS $0-2$ and mRS 3-6 from the procedure to 12 months.

\section{Mortality/Morbidity at 1 Year}

At 12 months, 59 of the 62 patients enrolled in the study were clinically evaluated with mRS scoring. Three patients included in the 30-day mortality/morbidity analysis were not included in the 1-year mortality/morbidity (1 patient not treated with WEB, 1 patient retreated before 1 year, and 1 patient lost to follow-up were not evaluated).

Two patients died between 1-month and 1-year follow-up: 1 unrelated to aneurysm disease or treatment and 1 from worsening of pre-existing mass effect described previously. All-cause mortality was $2 / 59$ (3.4\%), and neuro-related mortality was $1 / 59$ (1.7\%). The 2 patients who had an $\mathrm{mRS}$ of $>2$ at 1 month were improved at 1 year (mRS 1 and 2); this outcome led to no morbidity at 1 year.

\section{Retreatment}

One patient with aneurysm recanalization was retreated at 6 months by using a flow diverter. One patient had an attempted retreatment at 10 months with a flow diverter, which was unsuccessful.

\section{Anatomic Results at 1 Year}

Of the 63 aneurysms in the intention-to-treat population, aneurysm occlusion was evaluated in 58 aneurysms at 1 year. The vascular imaging technique was digital subtraction angiography in $50 / 58(86.2 \%)$ cases, CTA in 3 cases (5.2\%), and MRA in 5 cases $(8.6 \%)$. Aneurysm occlusion was not evaluated in 1 patient who was not treated with a WEB, 1 patient who had retreatment before 1 year (see above), 1 patient lost to follow-up, and 2 patients who died before 1 year (see above).

Complete occlusion was observed in 30/58 aneurysms $(51.7 \%)$ in the global population, in $14 / 28(50.0 \%)$ patients treated with WEB DL, and in $16 / 30(53.3 \%)$ patients treated with WEB SL/SLS.

Neck remnant was observed in $16 / 58$ aneurysms (27.6\%) in the global population, in $8 / 28(28.6 \%)$ patients treated with WEB $\mathrm{DL}$, and in $8 / 30(26.7 \%)$ patients treated with WEB SL/SLS.

Aneurysm remnant was observed in 12/58 aneurysms (20.7\%) in the global population, in $6 / 28(21.4 \%)$ patients treated with WEB DL, and in 6/30 (20.0\%) patients treated with WEB SL/SLS.

\section{DISCUSSION}

The WEB French Observatory is, to date, the largest multicenter, prospective, Good Clinical Practice series dealing with WEB aneurysm treatment. Short and midterm follow-ups confirm the safety and efficacy of this treatment. At 1 month and 1 year, there was no mortality related to the treatment. Low morbidity was reported at 1 month (3.2\%), with clinical improvement at 1 year leading to no morbidity at that time point. At 1 year, complete aneurysm occlusion was observed in $51.7 \%$ of aneurysms, with adequate occlusion (complete occlusion and neck remnant) in $79.3 \%$.

New technologies for the endovascular treatment of intracranial aneurysms must be carefully evaluated for safety and efficacy; this evaluation has not always been performed in the past. For aneurysm treatment with the WEB device, careful evaluation of safety and efficacy has been built through a series of prospective, Good Clinical Practice clinical studies (French Observatory, WEBCAST, and WEBCAST 2 and the ongoing WEB Intrasaccular Therapy study under an FDA investigational device exemption). The French Observatory study was conducted during the early phase of clinical use of the WEB and included the learning curve with the WEB in terms of procedural technique, WEB sizing, and the approach to antiplatelet therapy. It shows that WEB treatment permits the management of ruptured, unruptured, recanalized, and complex wide-neck bifurcation aneurysms located at the MCA, anterior communicating artery, ICA terminus, and basilar artery with a very high success rate (98.4\%). Despite the use of a relatively large microcatheter, the treatment appears to be feasible in the most cases.

The current results confirm the great safety of WEB treatment as has been reported in retrospective series and WEBCAST. ${ }^{10-17}$ The rate of thromboembolic events with the WEB (14.5\%) was quite similar to that reported in the Analysis of Treatment by Endovascular Approach of Nonruptured Aneurysms (ATENA) 
and Clinical and Anatomical Results In the Treatment of Ruptured Intracranial Aneurysms (CLARITY) series (respectively, $7.3 \%$ and $13.3 \%) .^{1,2}$ Only 1 patient $(1.6 \%$ ) had a permanent deficit. Most patients treated in this study had wide-neck aneurysms (90.5\% compared with $30.9 \%$ in ATENA), and the rate of TE events was higher in wide-neck aneurysms. ${ }^{19}$ The rate of intraoperative rupture was low (1 patient, 1.6\%) and comparable with the 2.0\% observed in ATENA and 3.7\% in CLARITY. ${ }^{1,2}$ Moreover, the intraoperative rupture was not symptomatic.

Safety is also confirmed at 12 months with 2 deaths unrelated to the treatment, no new morbidity, and clinical improvement of patients who had morbidity at 1 month. No significant delayed adverse events were observed, as is the case with flow diverters. Remarkably, no delayed aneurysm rupture or intracranial parenchymal hemorrhage was reported. ${ }^{20,21}$

The present results also highlight the high quality of aneurysm occlusion obtained with this technique, confirming the data from 6-month follow-up in the WEBCAST and from an already published retrospective European series. ${ }^{14,15,17}$ Complete occlusion, neck remnant, and aneurysm remnant were observed at 1 year in, respectively, $51.7 \%, 27.6 \%$, and $20.7 \%$. The clinical impact of neck remnant after WEB treatment is unknown and probably not different from that observed after coiling. However, long-term follow-up is clearly needed to evaluate this point and is foreseen for 2 years in the French Observatory and 5 years in other Good Clinical Practice studies (WEBCAST, WEBCAST 2).

In the European series, similar to these French Observatory results, complete and adequate occlusion was reported at midterm follow-up (median, 13 months) in, respectively, 69.0\% and $89.7 \%{ }^{14,15}$ This series also confirmed the long-term (median, 27 months) stability of WEB aneurysm treatment, showing complete and adequate occlusion in, respectively, $68.4 \%$ and $84.2 \%$. There was no worsening of aneurysm occlusion between the mid- and long term. Comparison with other techniques is difficult because no series really focused on wide-neck bifurcation aneurysms. In the Matrix and Platinum Science trial, a subgroup analysis was conducted showing that in unruptured aneurysms with wide necks (not necessarily bifurcation), the rate of complete and adequate occlusion (at 12 months) was, respectively, $20.3 \%$ and $49.1 \%$ with coils and $45.7 \%$ and $78.6 \%$ with stent placement and coiling. ${ }^{22}$ If anatomic results with stent placement and coiling are relatively similar to those observed with the WEB, safety is worse with stent placement and coiling.

In a recent article, Cognard and Januel ${ }^{23}$ reported on their initial experience with WEB aneurysm treatment. At short-term follow-up, among 14 aneurysms, 1 was completely occluded $(7.2 \%)$ and neck and aneurysm remnants were observed in, respectively, $9(64.3 \%)$ and $4(28.6 \%)$ aneurysms. Long-term follow-up (mean, 18.6 months) was obtained in a very limited number of 7 patients and showed worse results. Indeed, this series was a very small, monocenter, self-analyzed report, dealing with complex aneurysms treated at the very beginning of the WEB experience. However, it introduces the concept of WEB shape modification with time, a parameter that was not analyzed in the French Observatory series.

Patients included in the French Observatory study were treated with Dual- or Single-Layer devices. Previous analyses showed a similar safety of treatment with the devices, with a trend toward less thromboembolic events in patients treated with Single-Layer devices. ${ }^{16}$ Anatomically, results were similar in both groups of patients, with complete occlusion in $50.0 \%$ of patients treated with WEB DL, $53.3 \%$ of patients treated with WEB SL/ SLS, and adequate occlusion in, respectively, $78.6 \%$ and $80.0 \%$.

This study has several limitations. First, the population was relatively small (62 patients). However, it is the first prospective, multicenter study evaluation with high-quality methodology evaluating the midterm safety and efficacy of this treatment. Second, it was not a randomized study, and comparison with other techniques was not easy. However, safety data are excellent and quite comparable with those observed in large coiling series. Efficacy data are more difficult to compare with those in historical series because most were mixed sidewall and bifurcation and narrow- and wide-neck aneurysms. Third, the potential WEB "compression" phenomenon has not been evaluated, to our knowledge. Further work will be conducted on this topic.

\section{CONCLUSIONS}

This study, with independent analysis of clinical events and anatomic results, confirms the very good safety profile of WEB treatment for bifurcation aneurysms, with rates of thromboembolic events and intraoperative rupture comparable with those observed with standard coiling and very low morbidity and mortality rates. A high rate of complete (51.7\%) and adequate occlusion $(79.3 \%)$ was obtained at 1-year follow-up.

Disclosures: Laurent Pierot-RELATED: Consulting Fee or Honorarium: Sequent Medical; UNRELATED: Consultancy: Covidien/ev3, MicroVention, Neuravi. Jacques Moret-UNRELATED: Consultancy: MicroVention, Covidien. Francis TurjmanRELATED: Other: Sequent Medical, Comments: fees by cases included in the registry; UNRELATED: Consultancy: Medtronic, * Codman, ${ }^{*}$ Stryker Neurovascular*; Grants/ Grants Pending: Medtronic*; Payment for Development of Educational Presentations: Codman, * Balt.* Denis Herbreteau—RELATED: Consulting Fee or Honorarium: Sequent Medical (proctoring); Support for Travel to Meetings for the Study or Other Purposes: Sequent Medical (proctoring, congress). Xavier Barreau-RELATED: Fees for Participation in Review Activities such as Data Monitoring Boards, Statistical Analysis, Endpoint Committees, and the Like: Sequent Medical lab; UNRELATED: Consultancy: Stryker, Codman, MicroVention. Christophe Cognard-RELATED: Consulting Fee or Honorarium: Sequent Medical; UNRELATED: Consultancy: MicroVention, Stryker, Codman, Medtronic, Sequent Medical. Andrew MolyneuxRELATED: Consulting Fee or Honorarium: Sequent Medical, Comments: for regulatory advice and independent clinical event adjudication; Support for Travel to Meetings for the Study or Other Purposes: Sequent Medical; Fees for Participation in Review Activities such as Data Monitoring Boards, Statistical Analysis, Endpoint Committees, and the Like: Sequent Medical; UNRELATED: Expert Testimony: clinical negligence cases in the UK and Ireland. James Byrne-RELATED: Grant: Sequent Medical, ${ }^{*}$ Comments: I provided a core laboratories reading service for this study paid for by the manufacturer of the WEB device; Support for Travel to Meetings for the Study or Other Purposes: Sequent Medical; UNRELATED: Board Membership: Stryker UK Ltd, Comments: clinical event adjudicatory for an unrelated registry. Laurent Spelle_UUNELATED: Consultancy: Stryker, Medtronic; Payment for Lectures (including service on Speakers Bureaus): Stryker, Medtronic. *Money paid to the institution.

\section{REFERENCES}

1. Cognard C, Pierot L, Anxionnat R, et al, Clarity Study Group. Results of embolization used as the first treatment choice in a consecutive nonselected population of ruptured aneurysms: clinical results of the Clarity GDC study. Neurosurgery 2011;69:837-41; discussion 842 CrossRef Medline

2. Pierot L, Spelle L, Vitry F; ATENA Investigators. Immediate clinical outcome of patients harboring unruptured intracranial aneurysms 
treated by endovascular approach: results of the ATENA study. Stroke 2008;39:2497-504 CrossRef Medline

3. Pierot L, Cognard C, Spelle L, et al. Safety and efficacy of balloon remodeling technique during endovascular treatment of intracranial aneurysms: critical review of the literature. AJNR Am J Neuroradiol 2012;33:12-15 CrossRef Medline

4. Pierot L, Spelle L, Leclerc C, et al. Endovascular treatment of unruptured intracranial aneurysms: comparison of safety of remodeling technique and standard treatment with coils. Radiology 2009;251: 846-55 CrossRef Medline

5. Pierot L, Cognard C, Anxionnat R, et al; CLARITY Investigators. Remodeling technique for endovascular treatment of ruptured intracranial aneurysms had a higher rate of adequate postoperative occlusion than did conventional coil embolization with comparable safety. Radiology 2011;258:546-53 CrossRef Medline

6. Shapiro M, Becske T, Sahlein, et al. Stent-supported aneurysm coiling: a literature survey of treatment and follow-up. AJNR Am J Neuroradiol 2012;33:159-63 CrossRef Medline

7. Pierot L. Flow diverter stents in the treatment of intracranial aneurysms: where are we? J Neuroradiol 2011;38:40-46 CrossRef Medline

8. Berge J, Biondi A, Machi P, et al. Flow-diverter Silk stent for the treatment of intracranial aneurysms: 1-year follow-up in a multicenter study. AJNR Am J Neuroradiol 2012;33:1150-55 CrossRef Medline

9. Pierot L, Wakhloo AK. Endovascular treatment of intracranial aneurysms: current status. Stroke 2013;44:2046-54 CrossRef Medline

10. Pierot L, Liebig T, Sychra V, et al. Intrasaccular flow-disruption treatment of intracranial aneurysms: preliminary results of a multicenter clinical study. AJNR Am J Neuroradiol 2012;33:1232-38 CrossRef Medline

11. Pierot L, Klisch J, Cognard C, et al. Endovascular WEB flow disruption in middle cerebral artery aneurysms: preliminary feasibility, clinical, and anatomical results in a multicenter study. Neurosurgery 2013;73:27-34; discussion 34-35 CrossRef Medline

12. Papagiannaki C, Spelle L, Januel AC, et al. WEB intrasaccular flow disruptor-prospective, multicenter experience in 83 patients with 85 aneurysms. AJNR Am J Neuroradiol 2014;35:2006-11 CrossRef Medline

13. Mine B, Pierot L, Lubicz B. Intrasaccular flow-diversion for treat- ment of intracranial aneurysms: the Woven EndoBridge. Expert Rev Med Devices 2014;11:315-25 CrossRef Medline

14. Lubicz B, Klisch J, Gauvrit JY, et al. WEB-DL endovascular treatment of wide-neck bifurcation aneurysms: short- and midterm results in a European study. AJNR Am J Neuroradiol 2014;35:432-38 CrossRef Medline

15. Pierot L, Klisch J, Liebig T, et al. WEB-DL endovascular treatment of wide-neck bifurcation aneurysms: long-term results in a European series. AJNR Am J Neuroradiol 2015 Jul 30. [Epub ahead of print] CrossRef Medline

16. Pierot L, Moret J, Turjman F, et al. WEB treatment of intracranial aneurysms: indications, feasibility, complications, and 1-month safety results with WEB DL and WEB SL/SLS in the French Observatory. AJNR Am J Neuroradiol 2015;36:922-27 CrossRef Medline

17. Pierot $\mathrm{L}$, Costalat V, Moret J, et al. Safety and efficacy of aneurysm treatment with WEB: results of WEBCAST study. J Neurosurg 2015 Sep 18. [Epub ahead of print] CrossRef Medline

18. Fiorella D, Arthur A, Byrne J, et al., Interobserver variability in the assessment of aneurysm occlusion with the WEB aneurysm embolization system. J NeuroIntervent Surg 2015;7:591-95 CrossRef Medline

19. Pierot L, Cognard C, Anxionnat R, et al; CLARITY Investigators. Ruptured intracranial aneurysms: factors affecting the rate and outcome of endovascular treatment complications in a series of 782 patients (CLARITY study). Radiology 2010;256:916-23 CrossRef Medline

20. Mustafa W, Kadziolka K, Noudel R, et al. Direct carotid-cavernous fistula following intracavernous carotid aneurysm treatment with a flow-diverter stent: a case report. Interv Neuroradiol 2010;16:447-50 Medline

21. Tomas C, Benaissa A, Herbreteau D, et al. Delayed ipsilateral parenchymal hemorrhage following treatment of intracranial aneurysms with flow-diverter. Neuroradiology 2014;56:155-61 CrossRef Medline

22. Hetts SW, Turk A, English JD, et al; Matrix and Platinum Science Trial Investigators. Stent-assisted coiling versus coiling alone in unruptured intracranial aneurysms in the Matrix and Platinum Science trial: safety, efficacy, and mid-term outcomes. AJNR Am J Neuroradiol 2014;35:698-705 CrossRef Medline

23. Cognard C, Januel AC. Remnants and recurrences after the use of the WEB intrasaccular device in large-neck bifurcation aneurysms. Neurosurgery 2015;76:522-30; discussion 530 CrossRef Medline 